\title{
The prevalence of calcified carotid artery atheromas on the panoramic radiographs of patients with type 2 diabetes mellitus
}

\author{
Arthur H. Friedlander, DDS, ${ }^{a}$ and Linda A. Maeder, DDS, ${ }^{b}$ Los Angeles, Calif \\ VA GREATER LOS ANGELES HEALTHCARE SYSTEM, UCLA DENTAL SCHOOL, UCLA MEDICAL CENTER, \\ AND UNIVERSITY OF SOUTHERN CALIFORNIA DENTAL SCHOOL
}

\begin{abstract}
O bjective. Type 2 diabetes mellitus, which afflicts 15 million Americans, is associated with accelerated cervical carotid artery atherosclerosis and a heightened risk of stroke. This study attempted to determine the prevalence of calcified atherosclerotic lesions in a group of patients with type 2 diabetes mellitus.

Study design. The panoramic radiographs of 49 men (age range, 55 to 81; mean age, 66.2 years) receiving routine dental treatment and insulin for diabetes at a Department of Affairs Veterans clinic were evaluated for calcified atheromas. Age-match controls, free of diabetes, were assessed in a like manner. Statistical comparison of the atheroma prevalence rates was by means of the Fisher exact test, and statistical comparison of atherogenic risk factors was by means of $t$ test with Bonferroni adjustment and, where necessary, the Mann-W hitney $U$ test.

Results. The radiographs of the diabetics (mean age, 66.9 years) revealed that $20.4 \%$ had atheromas whereas those of the controls (mean age, 68.1 years) demonstrated that $4 \%$ had atheromas (a statistically significant difference; $P=.0275$ ). Also statistically significant was the prevalence of atherogenic risk factors (plasma glucose, low density lipoproteins, and serum triglycerides) identified in the diabetic group. The radiographic appearance of the atheromas manifested by both groups of individuals, however, was similar, with the lesions located $1.5-2.5 \mathrm{~cm}$ inferior-posterior to angle of the mandible.

Conclusions. People with type 2 diabetes have a greater prevalence of calcified atheromas on their panoramic radiographs than do nondiabetics.
\end{abstract}

(O ral Surg $O$ ral Med O ral Pathol O ral Radiol Endod 2000;89:420-4)

Type 2 diabetes mellitus (previously known as noninsulin-dependent diabetes mellitus) afflicts approximately 15 million Americans. ${ }^{1}$ These people are at heightened risk of stroke because hyperglycemia, hyperlipidemia, and a hypertension often associated with the disorder have been implicated as the cause of atherosclerosis of the cervical portion of the carotid artery. ${ }^{2}$ Panoramic radiography is capable of discern-ing calcified atherosclerotic lesions (atheromas) in the cervical carotid artery and is frequently used to assess the maxillofacial

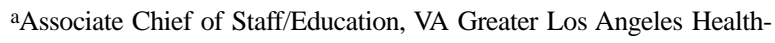
care System, Director of Quality Assurance, Hospital Dental Service, UCLA Medical Center, and Professor, Oral and Maxillofacial Surgery, UCLA School of Dentistry.

${ }^{\mathrm{b} C h i e f}$ of Periodontology, VA Los Angeles Ambulatory Care Center, and Clinical Assistant Professor of Periodontology, USC School of Dentistry.

Received for publication June 12, 1998; returned for revision Aug 3, 1998; accepted for publication Apr 19, 1999.

Copyright $@ 2000$ by Mosby, Inc.

$1079-2104 / 2000 / \$ 12.00+0 \quad \mathbf{7 / 1 3} / \mathbf{9 9 7 5 3}$

doi:10.1067/moe.2000.99753
}

complex of people with type 2 diabetes because of their known propensity to have oral infections. ${ }^{3-6}$ The scientific literature is silent, how-ever, as to the prevalence of atheromas on the radiographs of this high-risk group of patients. Therefore, we undertook a study to determine the prevalence of calcified atherosclerotic lesions among a group of patients with type 2 diabetes.

\section{MATERIAL AND METHODS Patients studied}

The members of the study group were gleaned from 94 consecutively treated outpatients attending the Diabetes Clinic at the Veterans Affairs Los Angeles Ambulatory Care Center. Inclusion criteria for the patients were (1) a diagnosis of type 2 diabetes (ie, in the unmedicated state, having a fasting plasma glucose [FPG] level > 126 $\mathrm{mg} / \mathrm{dL}$ on 2 separate occasions ${ }^{7}$ ), (2) daily insulin administration, (3) an age of 55 years or greater, and (4) the ability to sustain a panoramic radiograph. Exclusion criteria for the patients were (1) a history of a transient ischemic attack, (2) a history of a cerebrovascular acci- 
Table I. Comparison of risk factors for atherosclerosis

\begin{tabular}{lcccc}
\hline & $\begin{array}{c}\text { Diabetic study } \\
\text { sample }(n=49): \\
\text { mean } \pm S D\end{array}$ & $\begin{array}{c}\text { Age-matched } \\
\text { controls }(n=49): \\
\text { mean } \pm S D\end{array}$ & $\begin{array}{c}\text { t test or } \\
\text { Fischer exact test }\end{array}$ & $P$ value \\
\hline Age (mean \pm SD) & $66.2 \pm 5.7 \mathrm{y}$ & $65.8 \pm 7.3 \mathrm{y}$ & $t=0.35$ & $P=.724$ \\
Highest FPG (normal range, $70-110 \mathrm{mg} / \mathrm{dL})$ & $287 \pm 109 \mathrm{mg} / \mathrm{dL}$ & $120 \pm 16 \mathrm{mg} / \mathrm{dL}$ & $t=10.96$ & $P<.0001^{*}$ \\
Total serum cholesterol (normal range, $146-200 \mathrm{mg} / \mathrm{dL})$ & $191 \pm 39 \mathrm{mg} / \mathrm{dL}$ & $178 \pm 26 \mathrm{mg} / \mathrm{dL}$ & $t=1.91$ & $P=.06 \dagger$ \\
Serum LDL (normal range, $62-130 \mathrm{mg} / \mathrm{dL})$ & $132 \pm 59 \mathrm{mg} / \mathrm{dL}$ & $89 \pm 19 \mathrm{mg} / \mathrm{dL}$ & $t=4.85$ & $P<.0001$ \\
Serum triglycerides (normal range, $30-170 \mathrm{mg} / \mathrm{dL}$ & $184 \pm 104 \mathrm{mg} / \mathrm{dL} \ddagger$ & $88 \pm 19 \mathrm{mg} / \mathrm{dL}$ & $t=6.34$ & $P<.0001^{*}$ \\
Prevalence of hypertension & $44(90 \%)$ & $41(84 \%)$ & Fisher exact test & $P=.553$ \\
Presence of calcified carotid artery atherosclerosis & $10(20.4 \%)$ & $2(4 \%)$ & Fisher exact test & $P=.0275$ \\
\hline
\end{tabular}

*Levene test showed inequality of group variances that was not resolved through data transformation. Mann-Whitney $U$ test (nonparametric) confirmed significant group differences at $P<.0001$.

$\dagger$ Mann-Whitney $U$ test was not significant; $Z=1.56, P=.118$.

$\ddagger$ Two outliers with extremely high serum triglyceride levels $(>1100)$ were excluded from this group before data analysis.

dent, (3) female gender (because of the paucity of women in the proposed control population), and (4) poor radiographic image quality (because of overexposure or underexposure, incorrect patient positioning, and/or processing errors). All radiographic interpretations were performed solely by the senior author (A.H.F.). After 7 radiographs of poor quality were excluded, these criteria resulted in a study population of 49 people.

The members of the control group were gleaned from 314 consecutively treated male outpatients attending the Dental Clinic at the Veterans Affairs Ambulatory Care Center and Nursing Home in Sepulveda, California. Inclusion criteria for the control patients were (1) age match ( \pm 12 months) to the study population and (2) a satisfactory panoramic radiograph. Exclusion criteria for the control patients were (1) a history of diabetes mellitus, (2) a history of transient ischemic attack, and (3) a history of cerebrovascular accident. All radiographic interpretations were performed solely by the senior author (A.H.F.). After 5 radiographs of poor quality were excluded, these criteria resulted in a control population of 49 people.

\section{Equipment}

All patients were radiographed through use of the Panelipse II (Gendex Corp, Des Plaines, Ill) panoramic $\mathrm{x}$-ray system. The unit was operated at $4 \mathrm{~mA}$, the peak kilovoltage ranging from 70 to 80 depending on the estimate of the subject's jaw size. Kodak Dental Film/Ektamat: DFG-5 was used. The exposed radiographs were processed according to the manufacturer's directions. An automatic developer (A/T 2000, Air Techniques Inc) was used.

\section{Methods}

The radiographs were examined in subdued ambient light through use of transmitted light from a standard viewing box and a rheostat-controlled 75-W bulb ("hot" light) for the presence of a calcified carotid artery atheroma. Calcifications consistent with the diagnosis appear as single or multiple discrete radiopaque nodular masses within the soft tissues of the neck, $1.5 \mathrm{~cm}$ inferior and $2.5 \mathrm{~cm}$ posterior to the cortical rim of the midpoint of the mandibular angle. The lesions are separate and distinct from the hyoid bone and variably appear above or below this structure. ${ }^{8}$

The medical records of the study and control groups were reviewed for factors related to both diabetes and atherosclerosis. Specifically noted in each case were the highest FPG level during the past 2 years, the average percentage of hemoglobin $\mathrm{A} 1 \mathrm{C}\left(\% \mathrm{HbA}_{1 \mathrm{c}}\right)$, and the average total daily insulin (regular plus neutral protein Hagedorn [NPH]) requirement. Also recorded were the average total serum cholesterol level, the average serum low density lipoprotein (LDL) level, the average serum triglyceride level, and the prevalence of hypertension requiring medication for control.

Data analysis was carried out by comparing the proportions of diabetic and control groups with calcified carotid artery atheromas through use of the Fisher exact test. These groups were also compared with respect to each of the following atherosclerosis-associated risk factors through use of the $t$ test with Bonferroni adjustment ( $P$ level at .01): high FPG, total serum cholesterol, serum LDL, and serum triglyceride levels. If assumptions of equality of variance and normality (assumed for the $t$ test) were not met, data transformations (eg, natural log or square root) were performed and assumptions were rechecked. If this was not successful, the Mann-Whitney $U$ test (a nonparametric equivalent of the $t$ test) was performed as appropriate. Group differences in prevalence of hypertension were also tested through use of the Fisher exact test.

\section{RESU LTS}

The comparison between the diabetic study sample and controls is shown in Table I. The study sample consisted of 49 male patients with a mean age of 66.2 years (range, 55 to 81 years). During the preceding 2 years, these men 
Table II. Characteristics of patients with calcified carotid artery atherosclerosis

\begin{tabular}{lcc}
\hline Age & $66.5 \pm 4.0 \mathrm{y}$ & $69.0 \pm 18.3 \mathrm{y}$ \\
Highest FPG (normal range, $70-110 \mathrm{mg} / \mathrm{dL})$ & $310 \pm 87 \mathrm{mg} / \mathrm{dL}$ & $124 \pm 14 \mathrm{mg} / \mathrm{dL}$ \\
Total serum cholesterol (normal range, $146-200 \mathrm{mg} / \mathrm{dL})$ & $201 \pm 30 \mathrm{mg} / \mathrm{dL}$ & $169 \pm 16 \mathrm{mg} / \mathrm{dL}$ \\
Serum LDL (normal range, $62-130 \mathrm{mg} / \mathrm{dL})$ & $173 \pm 118 \mathrm{mg} / \mathrm{dL}$ & $82 \pm 6 \mathrm{mg} / \mathrm{dL}$ \\
Serum triglycerides (normal range, $30-170 \mathrm{mg} / \mathrm{dL})$ & $175 \mathrm{mg} / \mathrm{dL} \pm 99(\mathrm{n}=8)$ and & $89 \pm 1.4 \mathrm{mg} / \mathrm{dL}$ \\
& $1357 \mathrm{mg} / \mathrm{dL}(\mathrm{n}=2$ outliers) & $2(100 \%)$ \\
Prevalence of hypertension & $9(90 \%)$ & $1(50 \%) ; 1$ with bilateral \\
No. with unilateral carotid artery opacities & $6(60 \%) ; 4$ with bilateral & \\
\hline
\end{tabular}

averaged a high FPG level of $287 \mathrm{mg} / \mathrm{dL}$ (normal reference range, $70-110 \mathrm{mg} / \mathrm{dL}$ ) and a $\% \mathrm{HbA}_{1 \mathrm{c}}$ of 6.75 (normal reference range, 5.0-6.0), and they required a total daily insulin (regular plus NPH) dosage of 57 units. During this period, the average total serum cholesterol was $191 \mathrm{mg} / \mathrm{dL}$ (normal reference range, 146-200 $\mathrm{mg} / \mathrm{dL}$ ) and the average serum LDL value was 132 $\mathrm{mg} / \mathrm{dL}$ (normal reference range, $62-130 \mathrm{mg} / \mathrm{dL}$ ). The average serum triglyceride value, calculated after two outliers were omitted from the sample, was $184 \mathrm{mg} / \mathrm{dL}$ (normal reference range, $30-170 \mathrm{mg} / \mathrm{dL}$ ); the values for the outliers were 1110 and $1640 \mathrm{mg} / \mathrm{dL}$. Ninety percent of the members of this group had hypertension (a systolic pressure equal to or greater than $140 \mathrm{~mm} \mathrm{Hg}$ and/or a diastolic pressure equal to or greater than $90 \mathrm{~mm} \mathrm{Hg}$ ) and required medication for its management.

The control sample consisted of 49 age-matched male patients free of diabetes mellitus, with a mean age of 65.8 years (range, 55 to 82 years). During the preceding 2 years, these men averaged a high FPG level of 118 $\mathrm{mg} / \mathrm{dL}$, a total serum cholesterol level of $178 \mathrm{mg} / \mathrm{dL}$, a serum LDL level of $89 \mathrm{mg} / \mathrm{dL}$, and a serum triglyceride level of $88 \mathrm{mg} / \mathrm{dL}$. Eighty-four percent of the control patients had hypertension and required medication for its management.

Panoramic radiographs manifesting calcified carotid artery disease were seen in $10(20.4 \%)$ patients in the diabetic study sample and in $2(4 \%)$ of the control patients.

The proportion of patients with calcified carotid artery disease was significantly higher in the diabetic study sample, as measured by Fisher exact test $(P=$ .0275; Table II). The diabetics with atheromas on their radiographs had a mean age of 66.5 years and an age range of 60 to 73 years. Six of the diabetics had unilateral opacities and 4 had bilateral opacities; during the preceding 2 years, these men averaged a high FPG level of $310 \mathrm{mg} / \mathrm{dL}$ and a $\% \mathrm{HbA}_{1 \mathrm{c}}$ of 7.1 , and they required a total daily insulin dosage of 72 units. During the same period, the average total serum cholesterol level was $201 \mathrm{mg} / \mathrm{dL}$ and the average serum LDL level was $173 \mathrm{mg} / \mathrm{dL}$. There was, however, a marked disparity in serum triglyceride levels, 8 patients aver- aging $175 \mathrm{mg} / \mathrm{dL}$ and 2 others averaging $1357 \mathrm{mg} / \mathrm{dL}$. Nine patients had hypertension and required medication for its management.

The 2 members of the control group with atheroma formation on their radiographs had a mean age of 69 years and an age range of 56 to 82 years. During the preceding 2 years, these men averaged a high FPG level of $124 \mathrm{mg} / \mathrm{dL}$, a total serum cholesterol level of $169 \mathrm{mg} / \mathrm{dL}$, a serum LDL level of $82 \mathrm{mg} / \mathrm{dL}$, and a serum triglyceride level of $89 \mathrm{mg} / \mathrm{dL}$.

The diabetic study group and the control group were compared with respect to risk factors associated with atherosclerosis by means of the Fischer exact test or the $t$ test. Positively skewed data distributions with large standard deviations were observed in the diabetic group on measures of plasma glucose, serum cholesterol, LDLs, and serum triglycerides. Assumptions of equality of variances and normality were not met even after data transformation. The Mann-Whitney $U$ test, a nonparametric equivalent of the $t$ test, was therefore performed for these variables. As reported in Table I, plasma glucose values were significantly higher for the diabetic group than for the control group $(z=8.11, P<$ $.0001)$, as were values for LDLs $(z=6.70, P<.0001)$ and serum triglycerides $(z=5.99, P<.0001)$. However, the groups were not different with respect to total serum cholesterol $(z=1.56, P=.118)$.

\section{DISCU SSIO N}

The panoramic radiographs of patients with type II diabetes mellitus showed a higher prevalence of calcified atherosclerotic lesions of the carotid artery (20.4\%) than did those of matched control patients without diabetes $(4 \%)$. The difference in the prevalence rates of atheroma formation between these groups may have occurred because of the significantly greater burden among the diabetic group of risk factors (elevated levels of plasma glucose, serum LDLs, and serum triglycerides) known to be associated with the development of atherosclerosis.

The carotid atheromas seen in both populations had a similar morphologic appearance (Figs 1 and 2). The atheromas varied from single to multiple discrete 


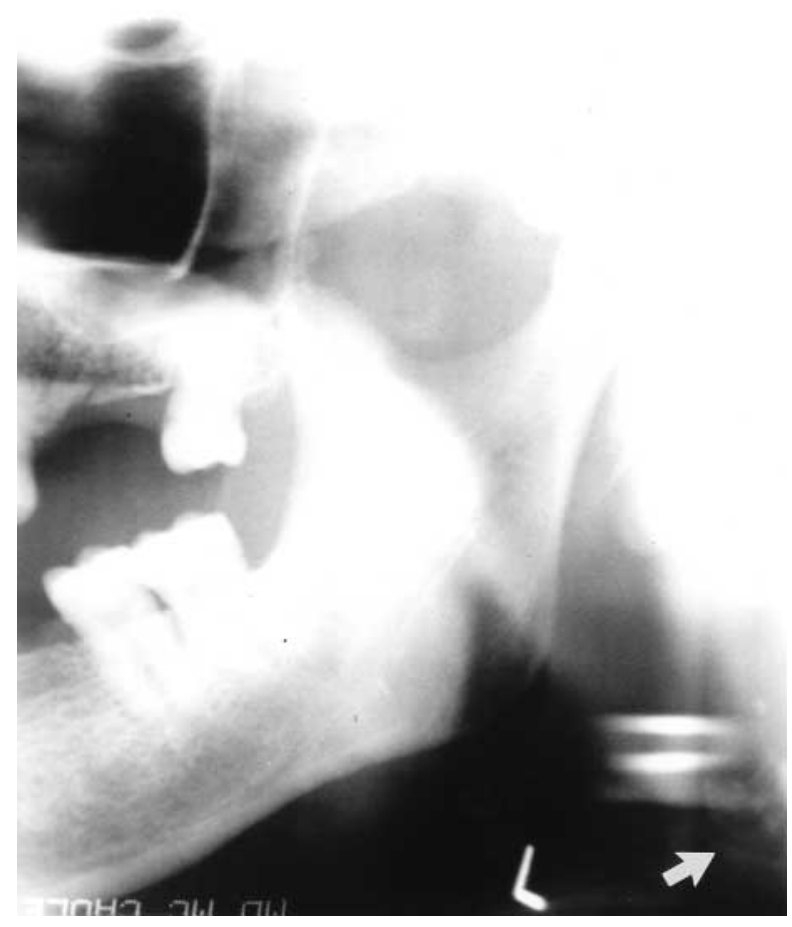

Fig 1. Portion of panoramic radiograph shows atherosclerotic lesion in left neck (arrow) of patient with type 2 diabetes mellitus.

radiopaque calcifications. They were located within the soft tissues of the neck, 1.5 to $2.5 \mathrm{~cm}$ inferior-posterior to the angle of the mandible. Their appearance and location differentiated them from anatomical entities (the stylomandibular and stylohyoid ligaments, hyoid bone, epiglottis) and pathologic entities (sialoliths, phleboliths, calcified lymph nodes) that variably appear contiguous to this region.

Type 2 diabetes mellitus is a disease complex with both metabolic and vascular components. The disease usually becomes clinically apparent after age 40 years in obese persons with a sedentary lifestyle and a family history of diabetes. Early in the disease there is increased production of glucose by the liver in the fasting state, and although adequate amounts of insulin are produced, defects in the molecule, altered cell receptors for insulin, and an unresponsiveness (resistance) to insulin's actions in target tissues (liver, muscle, fat) result in an elevation of the blood glucose level and an alteration in the lipid profile. $9,10 \mathrm{In}$ most patients the disease is initially managed through prescription of a low-calorie, low-saturated-fat diet, exercise, and the administration of oral hypoglycemic agents. Late in the disease process, however, more than $50 \%$ of patients require administration of exogenous

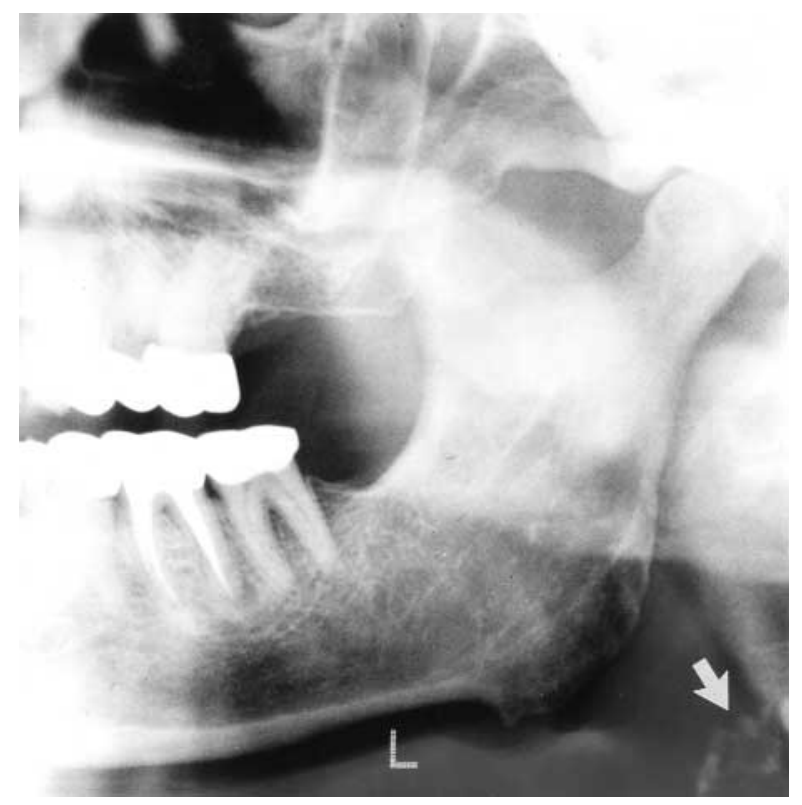

Fig 2. Portion of panoramic radiograph shows similarly appearing atherosclerotic lesion in left neck (arrow) of patient free of type 2 diabetes mellitus.

insulin to control hyperglycemia because the beta cells of the pancreas falter in their production of insulin.

The diagnosis of the disease and the efficacy of treatment are frequently determined by the FPG test and the $\% \mathrm{HbA}_{1 \mathrm{c}}$. The FPG test determines the level of glucose present in blood plasma at the time the sample is obtained. A diagnosis of diabetes mellitus is made when 2 FPG tests verify that the glucose level is equal to or exceeds $126 \mathrm{mg} / \mathrm{dL}$. Efficacy of treatment is determined by the $\% \mathrm{HbA}_{1 \mathrm{c}}$, which is formed when various sugars (most commonly, glucose) irreversibly bind to the hemoglobin molecule. The erythrocyte is freely permeable to glucose, and $\mathrm{HbA}_{1 \mathrm{c}}$ is formed ata rate proportional to the prevailing blood sugar concentration over a period of 2 to 3 months (the halflife of the cell). Tables exist that allow the clinician to translate the $\% \mathrm{HbA}_{1 \mathrm{c}}$ to an equivalent plasma glucose level. For example, a $\% \mathrm{HbA}_{1 \mathrm{c}}$ of 5 is equivalent to a plasma glucose level of $90 \mathrm{mg} / \mathrm{dL}$, a $\% \mathrm{HbA}_{1 \mathrm{c}}$ of 6 to a plasma glucose level of $120 \mathrm{mg} / \mathrm{dL}$, a $\% \mathrm{HbA}_{1 \mathrm{c}}$ of 7 to a plasma glucose level of $150 \mathrm{mg} / \mathrm{dL}$, and a $\% \mathrm{HbA}_{1 \mathrm{c}}$ of 8 to a plasma glucose level of $180 \mathrm{mg} / \mathrm{dL}$.

Advanced forms of vascular disease, which affect both small blood vessels (microvascular disease) and large blood vessels (macrovascular disease), develop in people with type 2 diabetes, especially those whose disease is poorly controlled.

Microvascular disease is characterized by increased basement membrane thickening, increased capillary 
permeability, and microthrombus formation. These changes are found throughout the vascular tree, but their major clinical effects are seen in the kidney (renal failure), retina (blindness), peripheral nerve (paresthesia, dysesthesia), myocardium (ischemia), and skin (ulceration).

Macrovascular disease is the major cause of morbidity and mortality (80\%) in type 2 diabetes. ${ }^{11,12}$ It is characterized by atherosclerotic changes in large blood vessels, and its major clinical effects are seen in the coronary arteries (angina, myocardial infarction), lower extremities (gangrene), and carotid artery (stroke).

Strokes caused by atherosclerosis (thrombus formation and emboli emanating from the plaques) at the bifurcation of the common carotid artery are 2 to 4 times more likely to occur in people with diabetes than in nondiabetics. ${ }^{13-17}$ The lesions arise because of prolonged hyperglycemia and the excessive production of LDLs (with a predominance of small dense particles). This adverse milieu induces circulating monocytes to pass through the carotid vessel's intact endothelial layer (at gap junctions) and lodge in the intimal wall, where they mature into macrophages. The small, dense lipoprotein particles also enter the arterial wall and are oxidized because of the hyperglycemic environment. The vast majority of the oxidized LDLs are then engulfed by the vascular wall macrophages. This process stimulates the macrophage to esterify the LDL, transforming itself into a foam cell. In a mechanism less well defined, oxidized LDL is also taken up by vascular wall smooth muscle cells, which then also undergo transformation into foam cells. This accumulation of foam cells constitutes the major component of the fatty streak that ultimately becomes the atheromatous plaque. ${ }^{18-21}$ Calcium salts taken up by the lesion during the maturation process correspond to radiopacities seen on radiographs.

The results of our study demonstrate that diabetes induced/accelerated macrovascular atherosclerosis in the region of the carotid artery bifurcation, a known cause of stroke, can be detected by means of conventional panoramic radiography. Such findings mandate a referral to the patient's physician for confirmation of the presence and extent of disease, inasmuch as control of risk factors, administration of medications, and surgery (endarterectomy) are safe and reliable methods of reducing the incidence of stroke. ${ }^{22,23}$

\section{REFEREN CES}

1. Cowie CC, Eberhardt MS, editors. The American Diabetes Association's diabetes 1996: vital statistics, Alexandria, Va; The Association; 1996. p. 13-20.

2. Uusitupa MI, Niskanen LK, Siitonen O, Voutilainen E, Pyorala K. Ten-year cardiovascular mortality in relation to risk factors and abnormalities in lipoprotein composition in type 2 (non-insulin- dependent) diabetic and non-diabetic subjects. Diabetologia 1993;36:1175-84.

3. Friedlander AH, Baker JD. Panoramic radiography: an aid in detecting patients at risk of cerebrovascular accident. J Am Dent Assoc 1994;125:1598-603.

4. Ueta E, Osaki T, Yoneda K, Yamamoto T. The prevalence of diabetes mellitus in odontogenic infections and oral candidiasis: an analysis of neutrophil suppression. J Oral Pathol Med 1993;22:168-74.

5. Gibson J, Lamey PJ, Lewis MAO, Frier BM. Oral manifestations of previously undiagnosed non-insulin dependent diabetes mellitus. J Oral Pathol Med 1990;19:284-7.

6. Sonis ST, Fazio RC, Fang L. Principles and practice of oral medicine. 2nd ed. Philadelphia: WB Sanders Co; 1995. p. 131-45.

7. American Diabetes Association. Report of the Expert Committee on the Diagnosis and Classification of Diabetes Mellitus. Diabetes Care 1997;20:1183-97.

8. Friedlander AH. Panoramic radiography: the differential diagnosis of carotid atheromas. Spec Care Dent 1995;15:223-7.

9. Jokl R, Laimins M, Klein RL, Lyons T J, Lopez-Virella MF, Colwell JA. Platelet plasminogen activator inhibitor 1 in patients with type II diabetes. Diabetes Care 994;17:818-23.

10. Atkinson MA, Maclaren NK. What causes diabetes? Sci Am 1990;263:62-3,66-71.

11. Andersson DKG, Svardsudd K. Long-term glycemic control relates to mortality in type II diabetes. Diabetes Care 1995; 18:1534-43.

12. Elkeles RS, Diamond JR, El-Bahghouti N, Dhanjil S, Nicolaides A, Geroulakos G, et al. Relative fasting hypoinsulinaemia and ultrasonically measured arterial disease in type 2 diabetes. Diabetic Med 1996;13:247-53.

13. Visona A, Lusiani L, Bonanome A, Beltramello G, Confortin L, Papesso B, et al. Wall thickening of common carotid arteries in patients affected by noninsulin-dependent diabetes mellitus: relationship to microvascular complications. Angiology 1995;46:793-9.

14. Biller J, Love BB. Diabetes and stroke. Med Clin North Am 1993;77:95-110.

15. Janku HU. Epidemiology and risk factors of macrovascular disease in diabetes mellitus. Horm Metab Res 1990;22(Suppl):8-11.

16: Lehto S, Ronnemaa T, Pyorala K, Laakso M. Predictors of stroke in middle-aged patients with non-insulin dependent diabetes. Stroke 1996;27:63-8.

17. Kuusisto J, Mykkanen L, Pyorala K, Laasko M. Non-insulin dependent diabetes and its metabolic control are important predictors of stroke in elderly subjects. Stroke 1994;25:1157-64.

18. Yamamoto M, Egusa G, Yamakido M. Carotid atherosclerosis and serum lipoprotein(a) concentrations in patients with NIDDM. Diabetes Care 1997;20:829-31.

19. Giugliano D, Ceriello A. Oxidative stress and diabetic vascular complications. Diabetes Care 1996;19:257-67.

20. Chait A, Bierman EL. Pathogenesis of macrovascular disease in diabetes. In: Kahn RC, Weir GC, editors. Joslin's diabetes mellitus. 13th ed. Philadelphia: Lea \& Febiger; 1994. p. 648-64.

21. Steinberg D, Pathasarathy S, Carew TE, Khoo JC, Mitztum JL. Beyond cholesterol: modification of Iow-density lipoprotein that increases atherogenicity. N Engl J Med 1989;320:915-24.

22. Butler RN, Rubenstein AH, Gracia AM, Zweig SC. Type 2 diabetes: causes, complications, and new screening recommendations. Geriatrics 1998;53:47-50,53-4.

23. Executive Committee for the Asymptomatic Carotid Atherosclerosis Study. Endarterectomy for asymptomatic carotid artery stenoses. JAMA 1995;273:1421-8.

Reprint requests:

Arthur H. Friedlander, DDS

Associate Chief of Staff/Education

VA Greater Los Angeles Healthcare System

16111 Plummer Street

Sepulveda, CA 91343 